\title{
Erratum to: Silicene on non-metallic substrates: Recent theoretical and experimental advances
}

Emilio Scalise $^{1}(\varangle)$, Konstantina Iordanidou' ${ }^{2}$, Valeri V. Afanas'ev ${ }^{2}$, André Stesmans $^{2}$, Michel Houssa $^{2}(\varangle)$

${ }^{1}$ Max-Planck-Institut für Eisenforschung, Max-Planck Straße 1, D-40237 Düsseldorf, Germany

${ }^{2}$ Department of Physics and Astronomy, University of Leuven, Celestijnenlaan 200D, B-3001 Leuven, Belgium

(C) Tsinghua University Press and Springer-Verlag GmbH Germany 2017

\section{Erratum to}

Nano Research 2018, 11(3): 1169-1182

https://doi.org/10.1007/s12274-017-1777-y

The name of the second author in the original version of this article was unfortunately wrongly written on page 1169 .

Instead of

Kostantina Iordanidou

It should read

Konstantina Iordanidou 